7. Reprod. Fert. (1966) 12, 229-232

BRIEF COMMUNICATION

\title{
THE SERIATIM REMOVAL OF FOETAL KITTENS
}

\author{
I. MaGANGE, J. W. PHILLIS ANd BEVERLEY WRIGHT \\ Department of Physiology, Monash University, Clayton, \\ Victoria, Australia
}

(Received 4th March 1966)

\begin{abstract}
Summary. Foetal and neonatal kittens were required for histochemical studies. They were removed from fourteen cats by laparotomy. Nine pregnancies continued and a further seven laparotomies were performed on four of the cats. Twenty-one foetuses were obtained in all and eight litters were born normally.
\end{abstract}

Foetal animals at a known stage of development are frequently required for biological experiments. The obvious means of meeting this need is to record the time of mating and subsequently to recover foetuses by autopsy. This presents unusual difficulties with cats, in the absence of special facilities to maintain them in a healthy condition during their relatively long period of gestation. Alternatively, chance-mated animals can be used, and foetal age estimated from foetal weight or dimensions. If gestation were continued these estimates could be checked against the date of parturition.

As part of an investigation of transmitter mechanisms in the cat cerebellum (McGance \& Phillis, 1964), we have studied the time course of appearance and distribution of cholinesterase-containing elements in the prenatal and neonatal feline cerebellum, using histochemical methods. (The results of this work will be reported elsewhere.)

The foetal material was obtained from pregnant individuals selected from unwanted cats collected weekly for this department. Single kittens provide ample material for histochemistry. It seemed, therefore, that the periodic removal of single foetuses from the same cat, and allowing it to produce a residual litter, would lead to: (a) economy of material, (b) the obtaining of specimens separated by known periods of time, and (c) the known date of parturition providing a check for earlier estimates of foetal age.

Cats were anaesthetized with a 50:50 mixture of pentobarbitone and thiopentone, given intravenously. Incisions were made in one or other flank or mid-ventrally, the operations being usually performed at approximately weekly intervals. Single foetuses were removed and the uterus and abdomen closed with gut sutures, using careful antiseptic precautions. The following standard procedures have become incorporated into our techniques, though there has been no opportunity of testing their efficacy objectively.

(1) Progesterone, $5 \mathrm{mg}$, was given intramuscularly in oil on the day of 229 
operation (or if the foetus weighed less than $10 \mathrm{~g}, 2 \mathrm{mg}$ ) and $2 \mathrm{mg}$ /day thereafter for 4 or 5 days, or until the next operation, if any. The object of this treatment was both to support the placentae and to reduce uterine irritability.

(2) The uterine incision was made close to the cervix, to avoid creating, above a residual foetus, a focus of contraction that might tend to expel it. The uterus from a cat that produced two normal kittens after three operations is shown in Plate 1.

(3) Antibiotics were given on the days of laparotomy.

The results of operations on fourteen cats are given in Table 1.

Loss of the remaining foetuses, when it happened, invariably followed the first laparotomy. This could well have been due to failure to pretreat with progesterone, since the post-operative doses of this substance constituted pretreatment for subsequent operations. Factors associated with the pre-operative experience of the cat-malnutrition, enteritis infection or psychological disturbances-could also have contributed.

To estimate foetal age the foetuses were weighed and crown-rump length (GR) measured. The latter proved unsatisfactory, chiefly for the lack of clear indication of how it should be measured. A plot of weight (w) against CR indicated that our GR measurements invariably exceeded those of Windle \&

TABLE 1

\begin{tabular}{|c|c|c|c|c|}
\hline \multirow{2}{*}{$\begin{array}{l}\text { Aborted or } \\
\text { foetuses } \\
\text { resorbed }\end{array}$} & \multicolumn{3}{|c|}{$\begin{array}{c}\text { Live births following } \\
n \text { operations }\end{array}$} & \multirow{2}{*}{$\begin{array}{c}\text { Killed after } 2 \\
\text { operations }\end{array}$} \\
\hline & $n=1$ & $n=2$ & $n=3$ & \\
\hline 5 & 5 & 1 & 2 & 1 \\
\hline
\end{tabular}

Griffin (1931). An alternative measure was devised, namely the length along the dorsal surface of the body from the vertex of the angle between muzzle and forehead, to the anus (CBA). CBA was measured in seventeen foetuses. Log $(\mathrm{CBA})$ and $\log (\mathrm{w})$ were so highly correlated $\left(r_{15}=0.98\right)$ that CBA seems hardly worthy of separate existence.

In Text-fig. 1 the curve has been constructed from the data of Coronois (1933, from Scott, da Silva \& Lloyd-Jacob, 1959). On this has been plotted the results from cats that provided more than one kitten. The first point (only weight known) has been shown associated with the mean age estimated from the curve. Subsequent ages have been calculated by adding the interval between laparotomies to these values. Few birth weights were recorded, most kittens having been suckled when first seen. In these cases horizontal lines have been drawn from the previous point to show the agreement between the gestation period so calculated and the theoretical time of 63 to 65 days (Asdell, 1946). It is clear that dating the foetus from the parturition, using a 63 days gestation time, would have underestimated foetal age in several instances (using weight as the criterion). In at least one case gestation could have been prolonged by progesterone, but in another, 12 days separated the last injection and parturition. 


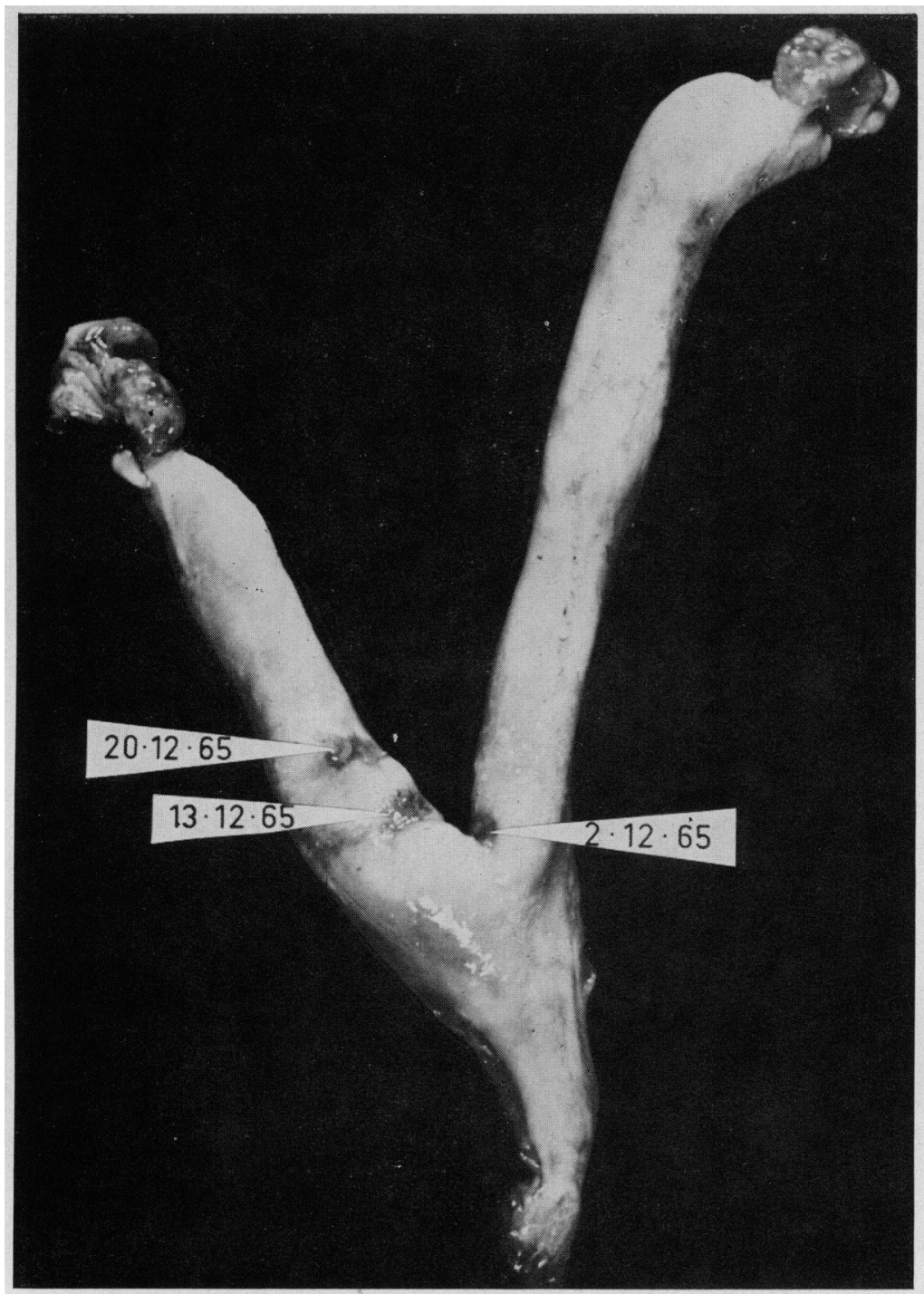

Uterus from cat 10 days after birth of a liter of two. Single focuses removed 26 , 15 and 8 days before birth. Scar sequence right on leli as indicated. 
The agreement with the curve in Text-fig. 1 of points after the first for each cat indicates that weight is probably the most reliable way of estimating foetal age. On this basis it might be argued that the successive operations had had little effect on the development of remaining foetuses. The only departures from the curve lie above it, suggesting that any change is in the direction of accelerated growth. This might have resulted from the relative increase in the availability of nutrients to residual foetuses.

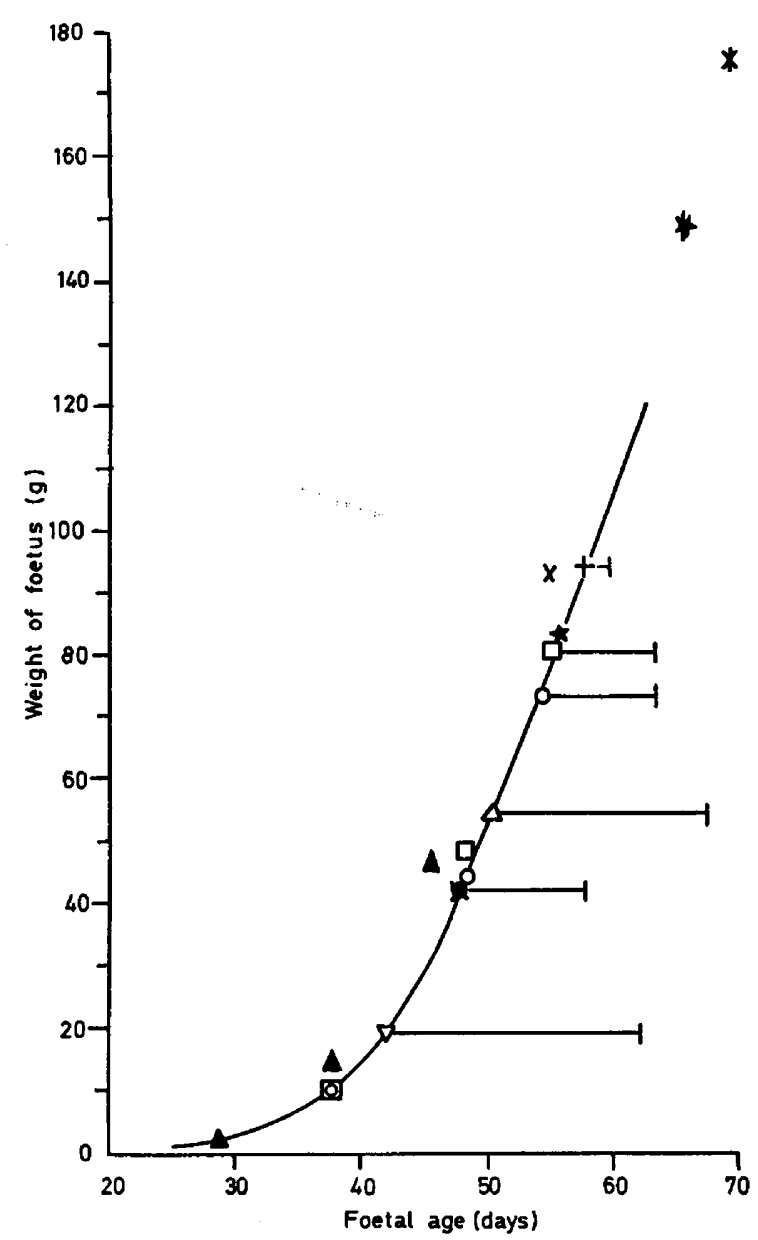

TExT-FIG. 1. Weight of foetuses or new-born kittens superimposed on curve drawn from data from Scott et al. (1959). Data for each cat have the same symbols. Where birth weights were not available a horizontal line has been used to show the interval from last operation to parturition.

It can be concluded that this procedure is perfectly feasible in the cat, the degree of success depending on care and the initial condition of the cat. Although in the present series only nine of the fourteen cats produced more than one kitten, the overall result was a considerable economy of material as twenty-nine foetuses-or-litters, in all, were obtained. 


\section{REFERENCES}

Asdell, S. A. (1946) Patterns of mammalian reproduction, p. 166. Comstock, New York.

Coronors, J. D. (1933) Development of behaviour in the foetal cat. Genet. Psychol. Monog. $14,283$. (cited by Scott et al., 1959).

McCance, I. \& Phillis, J. W. (1964) The action of acetylcholine on cells in cat cerebellar cortex. Experientia, 20, 217.

Scotr, P. P., DA Silva, A. G. \& Lloyd-JAcoв, M. A. (1959) The cat. In: The UFAW Handbook on the Care and Management of Laboratory Animals, 2nd edn. Ed. A. \& N. Worden. UFAW, London.

Windle, F. W. \& Griffin, A. M. (1931) Observations on embryonic and foetal movements of the cat. J. comp. Neurol. 52, 149. 